\title{
Parental Perception about Inhaler and Smoking at Home
}

\author{
Ng Sze Ka* \\ Department of Paediatrics and Adolescent Medicine, United Christian Hospital, Hospital Authority, Hong Kong
}

*Corresponding author: Ng Sze Ka, Department of Paediatrics and Adolescent Medicine, United Christian Hospital, Hospital

Authority, United Christian Hospital, 130 Hip Wo Street, Kung Tong, Hong Kong

\section{ARTICLE INFO}

Received: 幽 April 25, 2020

Published: 幽 May 07, 2020

Citation: Ng Sze Ka. Parental Perception about Inhaler and Smoking at Home. Biomed J Sci \& Tech Res 27(3)-2020. BJSTR. MS.ID.004516.

\begin{abstract}
Fear of treatment of asthma exists and leads to poor asthma control or poor quality of life. This paper aims to describe the parents of children with asthma perception about inhaler treatment and smoking at home. Parents of asthmatic children were invited to attend this semi-structure interview with open-ended questions and guided by a theme list which was conducted during the hospitalization of their children. There were four aspects concluded. A web application asthma education program to these children with asthma and their family was suggested.
\end{abstract}

Keywords: Parents; Asthma; Qualitative; Phobia; Smoking; Corticosteroid

\section{Introduction}

Parents feel psychological difficulties for managing children with asthma [1]. Fear of asthma treatment, such as corticosteroid or inhaler, exists and leads to poor asthma control in children or poor quality of life in children and their family. Many of carers mentioned that they were afraid of using asthma treatment particularly in corticosteroid [1,2]. They concerns the side effect of corticosteroids such as growth suppression, addiction or psychiatric disturbances. Some of carers used of complementary or alternative medicine, such as Chinese herbal medicine or supplement, to replace the inhaled medication [3]. This paper is reported the qualitative data of a clinical trial which aims to describe parents of children with asthma perception about inhaler treatment and smoking at home [4].

\section{Methods}

A trial was carried out at the acute respiratory unit in Hong Kong public Hospital after obtained approval from the ethics committee review board. The proposal of clinical trial had also been registered in the Chinese Clinical Trial Registry, World Health Organization Organisation (ChiCTR1800019706) and parental consents were obtained. There were 56 parents of children with asthma were invited to attend this interview. The children, aged 4-11 years, had admitted an pediatric acute unit by asthma attack during the study period from Oct 2018 to Jun 2019. Their parents were invited the semi-structure interview with open-ended questions and guided by a theme list which was conducted during hospitalization of their children. The interviews lasted about 15 to 20 mins. Content analysis was used to analyse the data from the face-to-face semistructure interviews with the participating parents. All the transcriptions were undertaken by the same person. Two health professionals who were bilingual (Cantonese and English) were involved in confirming the content of translation accuracy.

\section{Results}

There were four aspects concluded.

\section{Doubt about Asthma Diagnosis}

The asthma symptoms according to the new asthma concept, which is an allergy disease and controlled without primary symptoms such as repeated episodes of cough, wheezing and/or breathing difficulties. However, many of parents view on asthma is a disease which is difference with allergy airway. Some parents 
unable to differentiate the pneumonia wheeze or upper respiratory tract infection. Some parents began doubting the doctors' diagnosis of asthma and escaped the medical follow up.

\section{Steroid Phobia}

Parents of older asthmatic children have expressed a lot of concern about the adverse effects of corticosteroids, especially when their children start corticosteroid treatment at an older age. They perceived the effect of inhaled corticosteroids were harmful than the therapeutic function. One parent used the term "steroid abuse" when referring to the regular use of steroid. Another parents fear towards the adverse effect of steroid usage because of developing oral ulcer.

\section{Parental Perception}

Perception on Inhaler: Some parents perceived that the long term used of inhaled medication will lead to asthma. Some parents perceived the nebulizer delivery method was more effective than inhalers through valved holding chamber. Other parents suspected asthma symptoms due to inhaled medication.

Smoking at Home: Some parents believed that children with asthma who exposed to tobacco smoke at home indirectly that will not affect asthma control. Some parents claimed that they understood the harmful of smoking at home, however parents were not appropriate person for suggestion of quitting because the smoker was the elder member of the family. A few parents asked health professional for seeking the advice to these family members.

\section{Discussion and Perspectives}

This qualitative data indicates problems in health professionalpatient communication and concepts of asthma management. Firstly, the updated concept on allergy disease, like asthma, was not common in public. Many of parents unwanted their children were diagnosed of asthma even themselves had asthma or other allergy disease when their younger. Some of parents supposed asthma was an infectious disease, not a physiological disease, which can cured by treatment. Children would visited difference physician for chronic cough. Thus, physician cannot consider the medical history and reluctance to diagnose of asthma. Secondly, the conceptual vocabulary often differed between health professional and parents. Parents did not understand the "controlled" asthma means symptoms control. Many of parents believed that asthma controlled is no episode of unscheduled visits for asthma exacerbation. Lastly, the concept of third-hand smoking has not been followed specially for parents who were smoker or had incense at home. In conclusion, asthma is a chronic inflammatory immune disorder of the airways. However, many people were not understand this pathophysiology of asthma and fear of using the corticosteroid to control the immune. A web application asthma education to children with asthma and their family in enhancing their knowledge and self-management.

\section{Acknowledgement}

I would like to express my sincerest gratitude and thanks to my supervisors, Prof Janita Chau P C, and Prof Aileen Chan W K in the Chinese University of Hong Kong for their expert guidance throughout the study. Special acknowledgements also go to my colleagues Dr W K Chiu, Ms P K Ma, Dr J Cheng, Dr F Choi, Ms Li T Y, Ms Shek M Y in department Paediatrics and Adolescent Medicine of United Christian Hospital for their supporting and study reviewing.

\section{Conflict of Interest}

No conflict of interest exists.

\section{References}

1. Chong YY, Mak YW, Leung SP, Lam SY, Loke AY (2019) Acceptance and commitment therapy for parental management of childhood asthma: an RCT. Pediatrics 143(2): e20181723.

2. Hui RWH (2020) Inhaled corticosteroid-phobia and childhood asthma: Current understanding and management implications. Paediatric respiratory reviews 33: 62-66.

3. Ip KI, Hon KL, Tsang KYC, Leung TNH (2018) Steroid phobia, Chinese medicine and asthma control. The clinical respiratory journal 12(4): $1559-1564$.

4. Özçeker D, Uçkun U, İslamova D, Tamay Z, Güler N (2018) Corticosteroid phobia among parents of asthmatic children. The Turkish journal of pediatrics 60(2): 142-146.
ISSN: 2574-1241

DOI: 10.26717/BJSTR.2020.27.004516

Ng Sze Ka. Biomed J Sci \& Tech Res

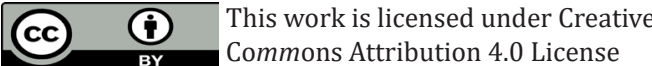

Submission Link: https://biomedres.us/submit-manuscript.php

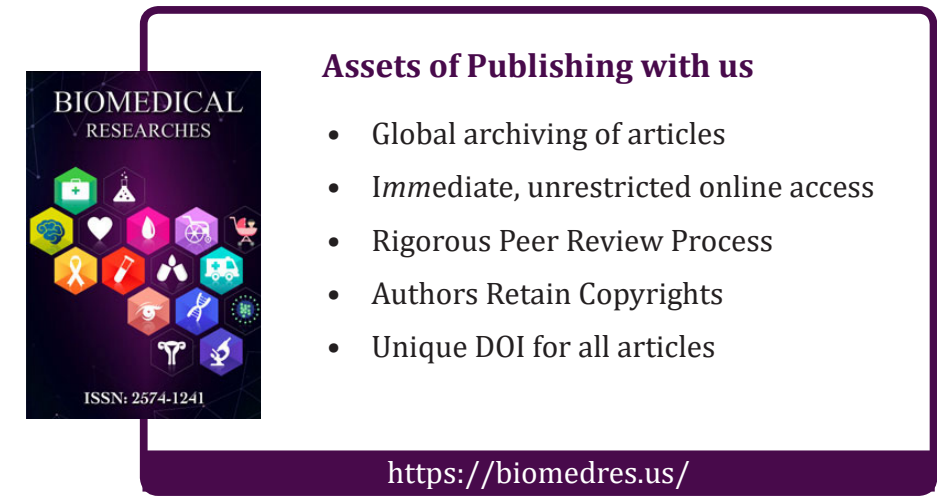

